\title{
The role of endocannabinoids in the control of eating disorders
}

\author{
Walter Milano', Mario F Tecce ${ }^{2}$ and Anna Capasso ${ }^{2}$ \\ ${ }^{1}$ Mental Health Operational Unit District 24 ASL Naples 1 Center, Italy \\ ${ }^{2}$ Department of Pharmacy, University of Salerno, Fisciano 84084, Italy
}

\begin{abstract}
Eating Disorder (ED) is a syndrome characterized by persistent alteration of eating behavior and the conditions that cause an insufficient ingestion and/or adsorption of foods. There are three different ED diseases: Anorexia Nervosa (AN), Bulimia Nervosa (BN) and Binge Eating Disorders (BED). ED are complex conditions that arise from a combination of long-standing behavioral, emotional, psychological, interpersonal, and social factors. The neuronal circuits that control the ingestion of food are mainly related to catecholaminergic, serotoninergic and peptidergic systems. In this respect, while serotonin, dopamine and prostaglandin promote the ingestion of food, by contrast, neuropeptide Y, norepinephrine, GABA and opioid peptides inhibit food ingestion thus causing the occurrence of ED. The drugs mainly used in the treatment of ED are antidepressants such as selective serotonin reuptake inhibitors and tricyclic antidepressant. Additionally, mood stabilizers (lithium), anxiolytics, serotonin and noradrenalin reuptake inhibitors and antipsychotic drugs are often used in the treatment of ED.
\end{abstract}

Several studies indicate that the endocannabinoid system is involved in ED supporting the idea that the cannabinoid signaling system is a key modulatory element in the activity in the brain area associated with ED.

\section{Introduction}

Eating disorders (ED) are complex systemic pathologies, with evidence of a tendency to chronic symptomatology with exacerbations and / or relapses, frequently ingraying with significant medical sequelae and psychiatric comorbidity [1]. They are characterized by aberrant and pervasive food patterns linked to the body image, the interiorization of an unreachable ideal of beauty with extreme dissatisfaction for one's own weight and body, low self-esteem, impulsiveness and, often, a structured perfectionism. In many cases, compensatory purging behaviors such as self-induced vomiting, laxative and diuretic abuse, excessive and unhealthy physical activity $[2,3]$ are associated.

These disorders are diseases with a high social impact and affect mainly the younger sections of the population and represent an important public health problem because they are associated with discomfort, disability and increased risk of death [4]. In addition, eating disorders have a high comorbidity with mood, anxiety and substance abuse disorders. They are difficult to diagnose and even more complicated to treat. They are considered one of the most common health problems affecting adolescents and young adults in Western countries [5].

An eating disorder comes into the mind and becomes the biggest concern until it absorbs almost every energy. The flow of life is marked by fixations and phobias related to the weight, diet, or image that is believed to have the body. Everything is decoded according to those parameters, and it grows up and burns in function of the rages and desperations that those themes evoke. They alter, ruin lives, careers, marriages, families, parenting. Existential projects that blend and degrade. Personal stories that are abandoning [6].

The ED are fairly common diseases, especially in the female population; Men represent $5-10 \%$ of all AN cases, $10-15 \%$ of BN cases, and $30-40 \%$ of BED cases. In the general population aged 18 and older, lifetime prevalence rates of $0.9 \%$ for Anorexia Nervosa (AN), 1.5\% for Bulimia Nervosa (BN) and 3, 5\% for the Binge Eating Disorder (BED); In women ages 18 to 24 , rates are much higher: $2 \%$ for $\mathrm{AN}, 4.5 \%$ for $\mathrm{BN}$ and $6.2 \%$ for BED. The incidence of AN is estimated to be at least 8 new cases per 100,000 people per year and for BN 12 new cases per 100,000 people per year. $[7,8]$.

Both in $\mathrm{AN}$ and $\mathrm{BN}$, the age range in which the debut is most common is between the ages of 15 and 19, with tendency to decrease in recent years, while for the BED it is distributed in a wider band with a peak in early adulthood $[4,9]$. There is, however, a significant difference between intercepted pathology and epidemiologically estimated disease, so many people with ED do not receive treatment; Additionally, those people with ED receive inappropriate care. They are among the most serious and less known psychiatric disorders by non-specialist doctors, with the highest mortality rates among psychiatric disorders; In fact, they have a death risk of 5 to 10 times greater than that found in healthy subjects comparable by age, with a mortality risk (MR) of 5.9 for AN and 1.9 for $\mathrm{BN}$ against the general population $[5,10]$.

ED are classified as mental illnesses and fall within the area of psychopathology, psychiatry and psychotherapy. However, the physical pathogenesis of $\mathrm{ED}$, or the use of the body as a means of extrinsic psychic suffering, can lead to significant, sometimes devastating,

Correspondence to: Anna Capasso, Department of Pharmacy, University of Salerno, Fisciano 84084, Italy annacap@unisa.it

Key words: endocannabinoids, eating disorders, neurobiology

Received: October 20, 2017; Accepted: November 10, 2017; Published: November 13, 2017 
complications for the patient, which increase not only the mortality but also chronicity and disability rate [11,23].

The interactions between the psychopathologic and organic components mean that all mental illnesses are those that have multiple areas of intersection with other areas of medicine and place them in a land border that make it difficult not only nosographic framing but also therapeutic approach [12]. From the onset of the disease and throughout its course, the psychic and somatic processes interact synergistically and continuously with each other and contribute to determining, maintaining and complicating all the characteristic syndromic constellation of the ED. Nutrition and related behaviors have consistently multiple valves that find their sense in the history and shape of the person and his reference group [11,13].

However, all these different clinical pictures, attributable to the DA, have found their own autonomy nosographic only in recent decades since the 70s of last century, with their entry in the DSM (Diagnostic and Statistical Manual of Mental Disorders) III to the present day our the fifth edition of the DSM. The recent DSM 5 [14], in attempting to reduce the many atypical forms falling into the diagnosis of "unhealthy eating disorder", proposed a new classification for ED and modified some previous diagnostic criteria. There are six major diagnostic categories and two residual categories in adults and adolescents and, moreover, it has made the diagnostic criteria for the three major categories $\mathrm{AN}, \mathrm{BN}$ and $\mathrm{BED}$ less restrictive.

The main nosogory categories are:

\section{- Anorexia nervosa}

- Bulimia nervosa

- Binge Eating Disorder

- Pica

- Mericity

\section{- Avoidance / Restrictive Food Disturbance}

However, this is not a complete picture; clinical and community studies indicate that it is not uncommon to detect an unrestricted eating disorder within these categories. In fact, there are two residual categories intended to accommodate partial or "subdominous" syndromes and other forms of problematic relationship with food:

1) Other specified nutrition and nutritional disorders is the substantial absence of binge eating and Night Eating Syndrome (NES). This ED includes forms for which the complete definitions of AN, BN or BED are not applicable as well as the elimination disorder (purging disorder: food disorder in which recourse is recurring with elimination pipes, mainly in the form of self-induced vomiting or excessive use of laxatives or diuretics)

2) Nutrition and nutrition disorders not specified, in this category go for nutrition and nutrition that the clinician can not specify due to lack of information.

However, ED tend to persist over the years and symptomatology (weight, frequency / absence of compensatory phenomena, etc.) employed for nosographic classification often tends to change over time with high cross-over rates estimated at around $30 \%$ of cases. In fact, a current diagnosis is defined at the time of all the symptoms needed to diagnose a lifetime diagnosis with an assessment of all symptoms and disorders throughout the course of the disease $[11,15]$.

\section{The ED Etiopathogenesis}

The ED etiopathogenesis is complex and multi-determined. The most accredited model is the bio-psycho-social model in which more than one factor develops from genetic to family, social and cultural factors [16]. Several studies (on families, twins, DNA) [17-23] seem to suggest that about $50 \%$ of the risk is due to genetic factors. Environmental risk factors can be multiple and are divided into early and late; Early Risk Factors are all those conditions that interfere with the early stages of neuro-development and maturation of stress response systems and include intrauterine life conditions, perinatal complications and early alterations in relationship with figures of care [24]. Late environmental risk factors can be considered conditions of loss or trauma, abuse and neglect in childhood, psychosocial stress and strongly conflicting relationships between parents and parents and children, psychoactive substance abuse and the exposure to pressures towards the thinness by members of the family group or the relational, affective, ethnic and cultural area in which the subject lives [4]. In fact, they engage in identification processes associated with canons of bodily perfection, the ideals of thinness as a synonym for beauty or towards an objectivation of the female body perceived, lived and shown in its sexual dimension, and thus treated as an object that must respond to an ideal of beauty and aesthetic perfection [16,17].

Being the ED of all mental illnesses involving and devastating more than the body and its biology, over the years, psychic and somatic processes interact with each other continually and contribute to the determination, maintenance and complication of symptoms. With the passing of time it becomes increasingly difficult to distinguish and address the primary factors that have triggered the pathological process from the side effects of malnutrition.

Genetic factors can significantly influence the regulation of neuronal circuits of brain areas used to control appetite and satiety.

Over the last decades it has been found that the appetite and hunger regulation system includes a large number of molecules that work from hormones, neurotransmitters and receptors. These molecules are produced in various organs, in the brain, in the adipose tissue, in the stomach, pancreas, intestines, and so on, and have multiple targets; The gut-brain axis expression refers to the bi-directional communication system that connects the digestive tract and the brain $[25,26]$. The network of signals that interact according to the state of the energy and energy requirements of the body and the energy reserves of the body is very complex and intricate. The energy-seeking and energy storage system seems to be more organized, articulate, efficient and redundant than the component used to consume any excess [27]. Such organization can best be explained in evolutionary terms, in fact, the push to look for and introduce energy and therefore food has been an essential condition of survival for organisms exposed to environments in which food availability was uncertain and inconsistent and energy expenditure to live was very high [28].

Several agents are involved in oressigenic circuits: they stimulate food research and ingestion, and the accumulation of energy reserves while others engage in anorexic circuits with the effect of reducing food ingestion. They have predominantly anorexic action on leptin, uncoupling protein UCP, peptide YY (PYY), pancreatic polypeptide ( $\mathrm{PP}$ polypeptide), $\beta 3$-adrenergic receptors ( $\beta 3$ adrenergic receptor $\beta 3-A R)$, Procomiomelanocortin (POMC), cholecystokinin (CCC) cholecystokinin, melanocyte stimulating hormone $(\mathrm{MCH})$, melanocortin 4 receptor (MC 4-R), release hormone of corticotropin $(\mathrm{CRH})$, peptide 1 similar glucagon (GLP 1), etc. However, there is a 
predominantly oressigenic action on the neuroptide Y (NPY), agoutirelated protein (AGRP), orexine A and B, grelin (ghrelin), opiate peptides (endorphins) and endocannabinoids [27-34].

Regarding the anatomical level, much of the cerebral formations involved in the governance of eating behaviors fall into the limbic system and include many phylogenetically older structures than the neocortex and have been found quite similar in the various species of mammals. It includes the hippocampus, the amygdaloid complex, the dorsal complex of the vague, the nucleus accumbens, the orbitofrontal cortex and the hypothalamus occupying a key position in the limbic system. Ultimately, the limbic system more than a well-defined anatomic area can be termed as a physiological and neuropsychological continuum. All of its components, interconnected by neuronal interconnection, are involved in emotional, emotional, motivational processes and hence in the organization of behaviors, in particular those related to the conservation of the individual and species, and therefore the reproductive, defensive functions, the access of children, breastfeeding and of course to eating behaviors and are associated with experiences of immediate satisfaction and pleasure. The limbic system and the neurotransmitters involved are therefore also connected to the reward system, especially in the connections involving two major neuronal groups: the ventral tegmental area and the accumbens nucleus, with dopamine as a neurotransmitter. The tegmental, stimulated, free dopamine that invests accumbens, prefrontal cortex, pale ventral, amygdala, septum. In addition to dopamine, endogenous opioids and endogenous cannabinoids also come into play [35-40].

Regarding the food control, at today, the predominantly accepted model indicates that homeostatic nutrition-related signals are linked to the reward system and thus to the experiences, feelings, emotions, memories that relate to the pleasure experience associated with satisfying the nutritional needs and motivating the subject to repeat the actions that give pleasure and satisfaction [39]. Disorder of the reward system, sometimes present in patients with $\mathrm{ED}$, produces abnormal activation and alterations in the release of dopamine, serotonin and endogenous opioids $[37,41,42]$.

\section{Cannabinoids and eating disorders}

The hypothalamic endocannabinoids have been shown to control food intake in both animals and humans, modulating eating behavior thus indicating that alterations of the endocannabinoid system could be involved in the pathophysiology of eating disorders [43,44].

Hypothalamic areas such as ventromedial, dorsomedial, and lateral hypothalamus, arcuate and paraventricular nuclei are involved in food intake control and feeding behavior [45]. These areas are interconnected with the neuronal pathways regulating the so-called 'reward' system. [46-48].

$\mathrm{CB} 1$ receptors are highly expressed in the above areas involved in reward thus indicating that the cannabinoid system is directly involved in feeding behavior [49-54].

Given the strong link between cannabinoids and reward circuitry, the role of endocannabinoids in the processes underlying the motivation to eat is an attractive hypothesis.

The mesolimbic dopaminergic system is one of the most important reward pathway [46] and a functional link between endocannabinoids and dopaminergic activity has been reported [55-58]. Therefore, a correlation between limbic endocannabinoid/dopamine levels and craving for tasty food is supposed to occur [55-59].
The interaction of the endogenous cannabinoid system with the serotoninergic system has been also studied according to the involvement of serotonin in the control of feeding behavior [60]. However, the administration of cannabinoid antagonist in rats combined with dexfenfluramine, a drug stimulating the release of serotonin, let to additive but not synergistic effects on reducing food intake, which is consistent with the hypothesis that the two pathways are working via independent mechanisms of action. [61].

Also, the endogenous opioid peptides are linked to central reward processes and there is increasing evidence supporting an important functional crosstalk between the opioid and the endocannabinoid system [62-69].

Finally, CB1 are present in the enteric nervous system. This area of $\mathrm{CB} 1$ expression might suggest the existence of a putative crosstalk between central and peripheral sites in the context of the roles of the cannabinoid system [70]. Therefore, the endocannabinoids are also involved in the peripheral regulation of feeding.

Animal models have represented an ideal tool to get further insights into the mechanism(s) involved in the cannabinoid-mediated stimulation of food intake. However, the magnitude of the effect of exogenous cannabinoids on food intake strictly depends on the dose used and do not increase linearly with the dose considering that low doses of cannabinoids appear to increase food intake whereas high doses seem to decrease it [71-77]. Furthermore, the route of administration of cannabinoid compounds represents another source of confusion [79-80].

Several investigations indicate that defects in endocannabinoid signaling may underlie eating disorders [81-83]. The endocannabinoid system and leptin interact functionally at the molecular level [84], therefore, the role played by both systems in the eating disorder as well as their therapeutic potential role was also studied [85].

Oleoylethanolamide, has been reported to promote satiety and lipolysis through the activation of the PPARa [86]. This molecule has an anorexigenic action by inducing oxytocin expression in the paraventricular nucleus of the hypothalamus and, interestingly, preliminary clinical results have shown altered levels of oleoylethanolamide in the cerebrospinal fluid and plasma of subjects recovered from eating disorders [87]. These preliminary observations could extend the findings of altered levels of eCBs in eating disorders to a more general involvement of acylethanolamides.

However, a genetic component in the eating disorder was also considered by performing studies to identify genes belonging to the endocannabinoid system genes involved in this pathology. In this respect, have been studied CNR1 and CNR2 (the genes encoding cannabinoid CB1Rs and CB2Rs, respectively), as well as the genes encoding the main enzyme responsible in the degradation of AEA (FAAH), NAAA (N-Acylethanolamine-hydrolyzing acid amidase [88-93].

The first family based study involved 52 families (parents with one or two affected siblings) that were genotyped for the (AAT) trinucleotide repeat of CNR1 gene. The distribution of alleles transmitted to the patients was not found to be significantly different from the nontransmitted parental alleles. However, upon dividing the samples to restricting and binging/purging subtypes of $\mathrm{AN}$, the data analysis revealed a preferential transmission of different alleles in each of the subtypes, suggesting restricting $\mathrm{AN}$ and binging/purging $\mathrm{AN}$ may be associated with different alleles of the CNR1 gene [88]. However, a subsequent study involving up to 91 German AN trios (patient 
with AN and both biological parents) was unable to confirm these results, nor did it show an association for any of 15 single nucleotide polymorphisms representative of regions with restricted haplotype diversity in FAAH, NAAA, and MAGL genes [89].

Another study in 115 overweight/obese subjects with bingeeating disorder, 74 non-binge-eating disorder patients with obesity and 110 normal weight healthy controls investigated one of these FAAH polymorphisms, previously implicated in obesity in bingeeating disorder, and reporting a lack of association [90] and in a more recent article these authors studied the association of this FAAH polymorphism and the CNR1 polymorphism in both $\mathrm{AN}$ and $\mathrm{BN}$, in 134 patients with $\mathrm{AN}, 180$ patients with $\mathrm{BN}$ and 148 normal weight healthy controls [91]. The authors found a significant increase in the frequency of both polymorphisms in $\mathrm{AN}$ and $\mathrm{BN}$ patients, a result in sharp contrast with the previous findings by Muller et al. [89] that showed a lack of association of these polymorphisms with AN. Additionally, Monteleone et al. [91] found a synergistic effect of the two polymorphisms in AN but not in BN.

Finally, a recent article has detected an association of a CNR2 polymorphism with both AN and BN [92] in a study comprising in 204 subjects with eating disorders and 1876 healthy volunteers in Japanese population. Taken together, the human genetic association studies show evidence of association between eCB system genes and eating disorders, but further studies are necessary to definitively confirm these findings.

\section{Therapeutic use of cannabinoid drugs in eating disorders}

Cannabis preparations have been used for both medicinal and recreational purposes for centuries. Its ancient medicinal use has been primarily related to ameliorate pain and increase appetite in disease states. However, because of their psychostimulant properties and the lack of an adequate body of knowledge, their use in western medicine has been excluded until recently. During the last 20 years this picture has dramatically changed. There has been an exponential increase in the knowledge of the molecular mechanisms underlying cannabinoid effects, and morphological, physiological and pathophysiological studies have shown that the molecular system supporting these effects (i.e., the eCB system), is ubiquitous and has a highly relevant role in maintaining whole body homeostasis and, especially, energy homeostasis [93]. This fact has led to an increased interest in the medical use of cannabinoid-related drugs. Thus, in 1985 the Food and Drug Administration approved Marinol' (dronabinol), a synthetically derived THC preparation, to relieve nausea, and vomiting associated with chemotherapy in cancer patients who have failed to respond adequately to other antiemetics, and in 1992 this compound was also approved for inducing appetite in AIDS patients suffering from cachexia [94,95]. Similarly, Nabilone (a synthetic cannabinoid that mimics THC) was also approved in 1985 for ameliorating the nausea of cancer chemotherapy. A more controversial step forward was the use of a cannabinoid CB1R antagonist/inverse agonist (rimonabant) for management of complicated obesity. Although the Food and Drug Administration never approved this drug, the European Medicine Agency did and Acomplia (the commercial name of rimonabant) was in the market for approximately 2 years. Despite the weight loss and improved cardiometabolic profile observed in obese patients, the drug had to be removed from the market due to its undesirable central side effects [96]. More recently, Sativex (the combination of THC and CBD) has been marketed in Canada and European countries like the United Kingdom and Spain for the treatment of spasticity due to multiple sclerosis, and it is currently in phase III clinical development for the treatment of cancer pain.

Taken into account the good therapeutic management of cannabinoids in cachexia and malnutrition associated with cancer and AIDS, it looks feasible that this kind of pharmacotherapy could be also useful in the treatment of eating disorders. Unfortunately, there are only two small trials assessing cannabinoid treatment in AN [85]. The former involved $11 \mathrm{AN}$ patients in a 4-week crossover trial and THC treatment resulted in increased sleep disturbances and interpersonal sensitivity, whereas there was no significant effect on weight gain [97]. Unfortunately, this study raised several concerns given it was an inpatient study and the occasional tube feeding was used. In addition, THC was compared to diazepam instead of placebo, which could be a confounding factor given diazepam has also been reported to increase food intake per se [98. The latter involved nine AN out-patients treated with THC. The results showed a significant improvement of depression and perfectionism scores without improving weight gain [99].

Currently, there is an ongoing phase III clinical trial involving 22 subjects to reveal if severe chronic AN patients treated with Marinol ${ }^{\circ}$ have significant improvement on weight, with secondary objectives of the study being evaluation of eating disorder inventory scale, motor and inner restlessness and endocrine parameters ${ }^{3}$ (EudraCT Number: 2007-005631-29). With this very limited number of performed trials (the last one being still not finished) it seems clear that no conclusions can be drawn out regarding the therapeutic validity of a cannabinoidbased approach in eating disorders. However, the satisfactory clinical use of cannabinoid agonists in other pathologies demands and encourages the development of further clinical trials on eating disorders patients. Interestingly, a very recent preclinical study in rodent have shown that the main active constituent of cannabis, THC, is able of reducing the weight loss associated with the development of AN via a mechanism involving reduced energy expenditure [100], thus providing encouraging preclinical data on the validity of a eCB-based therapy in $\mathrm{AN}$.

\section{Conclusions}

The present paper indicated that the endocannabinoid system plays an important role in the control of eating behavior by acting via central (brain) and peripheral (gut, liver, muscle and fat) mechanisms. The $\mathrm{CB} 1$ receptor is believed to be responsible for most of the central and peripheral effects of cannabinoids on the eating behavior. While some studies have clearly demonstrated that dysregulation of cannabinoid physiology can have detrimental effects on eating behavior, conversely, optimizing endocannabinoid tone appears to have beneficial effects on eating behavior regulation. Additional research is now needed to establish whether the observed changes are caused by the disease or whether these are neurochemical alterations that serve as risk factors for developing an eating disorder. Furthermore, these data indicate that the endocannabinoid system may be a potential new target for developing drugs to treat eating disorders.

\section{References}

1. Halmi KA (2013) Perplexities of treatment resistance in eating disorders. BMC Psychiatry 13: 292. [Crossref]

2. APA (2006) Practice guidelines for the treatment of patients with eating disorders. In Practice Guidelines for the Treatment of Psychiatric Disorders, 3rd edn (pp. 10971222). Arlington, VA: American Psychiatric Association.

3. Hay P, Chinn D, Forbes D, Madden S, Newton R, et al. (2014) New Zealand College of Psychiatrists clinical practice guidelines for the treatment of eating disorders. Australian \& New Zealand Journal of Psychiatry 48(11) 977-1008. 
4. Micali N, De Stavola B, Ploubidis G, Simonoff E, Treasure J, et al. (2015) Adolescent eating disorder behaviours and cognitions: gender-specific effects of child, maternal and family risk factors. The British Journal of Psychiatry 1-8.

5. Katherine A (2008) Halmi Salient components of a comprehensive service for eating disorders. World Psychiatry 8: 150-155

6. Nizzoli U, Colli C, Covri C “ DCA: Disturbi del Comportamento Alimentare” Caricci faber ed 2007

7. Hudson JI, Hiripi E, Harrison G, Pope Jr. HG, Kessler RC (2007) The prevalence and correlates of eating disorders inthe national comorbidity survey replication. Biological Psychiatry 61: 348-358.

8. Keski-Rahkonen A, Mustelin L (2016) Epidemiology of eating disorders in Europe: prevalence, incidence, comorbidity, course, consequences, and risk factors. Curr Opin Psychiatry 29: 340-345.

9. Volpe U, Tortorella A, Manchia, Monteleone AM, Albert U (2016) Monteleone P Eating disorders: What age at onset? Psychiatry Res 30: 238: 225-227.

10. Chesney E, Goodwin GM, Fazel S (2014) Risks of all-cause and suicide mortality in mental disorders: a meta-review. World Psychiatry 13: 153-160. [Crossref]

11. Scanelli G, Gualandi M, Simoni M, Manzato E (2013) Somatic involvement assessed through a cumulative score of clinical severity in patients with eating disorders. Eat Weight Disord

12. Capasso A. Petrella C, Milano W (2009) Recent clinical aspects of eating disorders. Reviews on Recent Clinical Trials Vol. 4. Pag.63-69

13. Bulik C, Hebebrand J, Keski-Rahkonen A, Klump K, Reichborn-Kjennerud KS, et al. (2007) Genetic epidemiology, endophenotypes, and eating disorder classification. Int J Eat Disord Suppl S52-S60.

14. American Psychiatric Association (2013) Diagnostic and Statistical Manual of Mental Disorders. Fifth Edition. Washington, DC: American Psychiatric Association.

15. Cuzzolaro Massimo "Anoressie e bulimie” il Mulino editore 2014.

16. Culbert KM, Racine SE, Klump KL (2015) Research Review: What we have learned about the causes of eating disorders - a synthesis of sociocultural, psychological, and biological research. J Child Psychol Psychiatry 56: 1141-1164. [Crossref]

17. Janet Treasure, Angélica M Claudino, Nancy Zucker Eating disorders Lancet 2010; 375: 583-93

18. Michele M. Easter (2012) "Not all my fault": Genetics, stigma, and personal responsibility for women with eating disorders. Social Science \& Medicine 75: $1408 \mathrm{e} 1416$

19. Boraska V, Franklin CS, Floyd JA, Thornton LM, Huckins LM, et al. (2014) A genomewide association study of anorexia nervosa. Mol Psychiatry 19: 1085-1094. [Crossref]

20. Sharan P, Sundar AS (2015) Eating disorders in women. Indian J Psychiatry 57: S286295. [Crossref]

21. Val-Laillet D, Aarts E, Weber B, Ferrari M, Quaresima V, et al. (2015) Neuroimaging and neuromodulation approaches to study eating behavior and prevent and treat eating disorders and obesity. Neuroimage Clin 8: 1-31

22. Yilmaz Z, Hardaway JA, Bulik CM (2015) Genetics and Epigenetics of Eating Disorders. Adv Genomics Genet 5: 131-150. [Crossref]

23. Sim LA, McAlpine DE, Grothe KB, Himes SM, Cockerill RG, et al. (2010) Identification and treatment of eating disorders in the primary care setting. Mayo Clin Proc 85: 746-751. [Crossref]

24. Favaro A, Tenconi E, Santonastaso P (2006) Perinatal factors and the risk of developing anorexia nervosa and bulimia nervosa. Arch Gen Psychiatry 63: 82-88.

25. Petra AI, Panagiotidou S, Hatziagelaki E, Stewart JM, Conti P, et al. (2015) GutMicrobiota-Brain Axis and Its Effect on Neuropsychiatric Disorders With Suspected Immune Dysregulation. Clin Ther 37: 984-995.

26. Mu C, Yang Y, Zhu W (2016) Gut Microbiota: The Brain Peacekeeper. Front Microbiol 7: 345. [Crossref]

27. Kaye W (2008) Neurobiology of anorexia and bulimia nervosa. Physiol Behav 94: 121135. [Crossref]

28. Roth J, Szulc AL, Danoff A (2011) Energy, evolution, and human diseases: an overview. Am J Clin Nutr 93: 875S-83. [Crossref]

29. Schwartz MW, Woods SC, Porte D Jr, Seeley RJ, Baskin DG (2000) Central nervous system control of food intake. Nature 404: 661-671. [Crossref]
30. Kaye W, Strober M, Jimerson D (2004) The neurobiology of eating disorders. In: Charney DS, Nestler EJ, editors. The neurobiology of mental illness. New York: Oxford Pres 112-128.

31. Monteleone P, Castaldo E, Maj M (2008) Neuroendocrine dysregulation of food intake in eating disorders. Regul Pept 149: 39-50. [Crossref]

32. Tong J, D'Alessio D (2011) Eating disorders and gastrointestinal peptides. Curr Opin Endocrinol Diabetes Obes 18: 42-49. [Crossref]

33. Angelica Lindén Hirschberg (2012) Sex hormones, appetite and eating behaviour in women. Maturitas 71: 48- 256

34. Tortorella A, Brambilla F, Fabrazzo M, Volpe U, Monteleone AM, Mastromo D (2014) Central and Peripheral Peptides Regulating Eating Behaviour and Energy Homeostasis in Anorexia Nervosa and Bulimia Nervosa: A Literature Review. Eur. Eat. Disorder Rev 22: $307-320$

35. Cota D, Marsicano G, Lutz B, Vicennati V, Stalla G, et al. (2003) Endogenous cannabinoid system as a modulator of food intake. Int J Obes Relat Metab Disord 27: 289-301.

36. Phillips M, Drevets WR, Lane R (2003) Neurobiology of emotion perception I: the neural basis of normal emotion perception. Biol Psychiatry 54:504-514

37. Walter H Kaye, Wagner A, Fudge JL, Paulus M (2011) Neurocircuity of Eating Disorders. Curr Topics Behav Neurosci.

38. Monteleone P, Maj M (2013) Dysfunctions of leptin, ghrelin, BDNF and endocannabinoids in eating disorders: beyond the homeostatic control of food intake. Psychoneuroendocrinology 38: 312-330. [Crossref]

39. Monteleone AM, Di Marzo V, Monteleone P, Dalle Grave R, et al. (2016) Responses of peripheral endocannabinoids and endocannabinoid-related compounds to hedonic eating in obesity. Eur J Nutr 55: 1799-1805. [Crossref]

40. Culbert KM, Racine SE, Klump KL (2016) Hormonal Factors and Disturbances in Eating Disorders. Curr Psychiatry Rep 18: 65. [Crossref]

41. Cassin SE, von Ranson KM (2005) Personality and eating disorders: a decade in review. Clin Psychol Rev 25: 895-916. [Crossref]

42. Giuliano C, Cottone P (2015) The role of the opioid system in binge eating disorder CNS Spectr 20: 537-545. [Crossref]

43. Klein TW (2005) Cannabinoid-based drugs as anti-inflammatory therapeutics. Nat Rev Immunol 5: 400-411. [Crossref]

44. Di Marzo V, Petrosino S (2007) Endocannabinoids and the regulation of their levels in health and disease. Curr Opin Lipidol 18: 129-140. [Crossref]

45. Schwartz MW, Woods SC, Porte D Jr, Seeley RJ, Baskin DG (2000) Central nervous system control of food intake. Nature 404: 661-671. [Crossref]

46. Spanagel R, Weiss F. The dopamine hypothesis of reward: past and current status Trends Neurosci 1999; 22: 521-527.

47. Gardner EL, Vorel SR (1998) Cannabinoid transmission and reward-related events Neurobiol Dis 5: 502-533. [Crossref]

48. Hoebel BG (1985) Brain neurotransmitters in food and drug reward. Am J Clin Nutr 42: $1133-1150$

49. Breivogel CS, Childers SR (1998) The functional neuroanatomy of brain cannabinoid receptors. Neurobiol Dis 5: 417-431.

50. Mechoulam R, Fride E (2001) Physiology. A hunger for cannabinoids. Nature 410: 763, 765. [Crossref]

51. Kunos G, Batkai S (2001) Novel physiologic functions of endocannabinoids as revealed through the use of mutant mice. Neurochem Res 26: 1015-1021.

52. Erickson JC, Clegg KE, Palmiter RD (1996) Sensitivity to leptin and susceptibility to seizures of mice lacking neuropeptide Y. Nature 381: 415-421. [Crossref]

53. Gallate JE, Saharov T, Mallet PE, McGregor IS (1999) Increased motivation for beer in rats following administration of a cannabinoid CB1 receptor agonist. Eur J Pharmacol 370: $233-240$.

54. Chaperon F, Thiebot MH (1999) Behavioral effects of cannabinoid agents in animals Crit Rev Neurobiol 13: 243-281.

55. Bisogno T, Berrendero F, Ambrosino G, Cebeira M, Ramos JA, et al. (1999) Brain regional distribution of endocannabinoids: implications for their biosynthesis and biological function. Biochem Biophys Res Commun 256: 377-380.

56. Hermann H, Marsicano G, Lutz B (2002) Coexpression of the cannabinoid receptor type 1 with dopamine and serotonin receptors in distinct neuronal subpopulations of the adult mouse forebrain. Neuroscience 109: 451-460. 
57. Glass M, Dragunow M, Faull RL (1997) Cannabinoid receptors in the human brain: a detailed anatomical and quantitative autoradiographic study in the fetal, neonatal and adult human brain. Neuroscience 77: 299-318. [Crossref]

58. Finlayson G, King N, Blundell JE (2007) Is it possible to dissociate 'liking' and 'wanting' for foods in humans? A novel experimental procedure. Physiol Behav 90 36-42. [Crossref]

59. Di Marzo V, Berrendero F, Bisogno T, Gonzalez S, Cavaliere P, et al. (2000) Enhancement of anandamide formation in the limbic forebrain and reduction of endocannabinoid contents in the striatum of delta9-tetrahydrocannabinol-tolerant rats. J Neurochem 74: 1627-1635.

60. Vickers SP, Dourish CT, Kennett GA (2001) Evidence that hypophagia induced by $\mathrm{d}$-fenfluramine and d-norfenfluramine in the rat is mediated by 5 -HT2C receptors. Neuropharmacology 41: 200-209.

61. Rowland NE, Mukherjee M, Robertson K (2001) Effects of the cannabinoid receptor antagonist SR 141716, alone and in combination with dexfenfluramine or naloxone, on food intake in rats. Psychopharmacology (Berl) 159: 111-116. [Crossref]

62. Navarro M, Carrera MR, Fratta W, Valverde O, Cossu G, et al. (2001) Functional interaction between opioid and cannabinoid receptors in drug self-administration. $J$ Neurosci 21: 5344-5350.

63. Cooper SJ, Kirkham TC (1993) Opioid mechanisms in the control of food consumption and taste preferences. In: Herz A, Akil H, Simon EJ (eds.) Handbook of experimental pharmacology. Springer-Verlag: Berlin pp 239-263.

64. Kirkham TC, Williams CM (2001) Synergistic efects of opioid and cannabinoid antagonists on food intake. Psychopharmacology (Berl) 153: 267-270. [Crossref]

65. Williams CM, Kirkham TC (2002) Reversal of delta 9-THC hyperphagia by SR141716 and naloxone but not dexfenfluramine. Pharmacol Biochem Behav 71: 333-340. [Crossref]

66. Crawley JN, Corwin RL (1994) Biological actions of cholecystokinin. Peptides 15: 731-755. [Crossref]

67. Marsicano G, Lutz B. Expression of the cannabinoid receptor CB1 in distinct neuronal subpopulations in the adult mouse forebrain. Eur J Neurosci 1999; 11: 4213-4225

68. Wiesenfeld-Hallin Z, de Araúja Lucas G, Alster P, Xu XJ, Hökfelt T (1999) Cholecystokinin/opioid interactions. Brain Res 848: 78-89. [Crossref]

69. Beinfeld MC, Connolly K (2001) Activation of CB1 cannabinoid receptors in rat hippocampal slices inhibits potassium-evoked cholecystokinin release, a possible mechanism contributing to the spatial memory defects produced by cannabinoids. Neurosci Lett 301: 69-71.

70. Fu J, Oveisi F, Gaetani S, Lin E, Piomelli D (2005) Oleoylethanolamide, an endogenous PPAR-alpha agonist, lowers body weight and hyperlipidemia in obese rats. Neuropharmacology 48: 1147-1153. [Crossref]

71. Carlini EA, Kramer C (1965) Effects of Cannabis sativa (marihuana) on maze performance of the rat. Psychopharmacologia 7: 175-181. [Crossref]

72. Dewey WL, Harris LS, Kennedy JS (1972) Some pharmacological and toxicological effects of 1-trans- 8 and 1-trans- 9 -tetrahydrocannabinol in laboratory rodents. Arch Int Pharmacodyn Ther 196: 133-145.

73. Thompson GR, Fleischman RW, Rosenkrantz H, Braude MC (1974) Oral and intravenous toxicity of delta9-tetrahydrocannabinol in rhesus monkeys. Toxicol Appl Pharmacol 27: 648-665. [Crossref]

74. Manning FJ, McDonough Jr JH, Elsmore TF, Saller C, Sodetz FJ (1971) Inhibition of normal growth by chronic administration of delta-9-tetrahydrocannabinol. Science 174: $424-426$

75. Sjödén PO, Järbe TU, Henriksson BG (1973) Influence of tetrahydrocannabinols (delta8-THC and delta9-THC) on body weight, food, and water intake in rats. Pharmacol Biochem Behav 1: 395-399. [Crossref]

76. Fernandes M, Schabarek A, Coper H, Hill R (1974) Modification of delta9-THC-actions by cannabinol and cannabidiol in the rat. Psychopharmacologia 38: 329-338. [Crossref]

77. Sofia RD, Barry H 3rd (1974) Acute and chronic effects of delta9-tetrahydrocannabinol on food intake by rats. Psychopharmacologia 39: 213-222. [Crossref]

78. Brown JE, Kassouny M, Cross JK (1977) Kinetic studies of food intake and sucrose solution preference by rats treated with low doses of delta9-tetrahydrocannabinol. Behav Biol 20: 104-110.

79. McLaughlin CL, Baile CA, Bender PE (1979) Cannabinols and feeding in sheep. Psychopharmacology (Berl) 64: 321-323. [Crossref]

80. Van Den Broek GW, Robertson J, Keim DA (1979) Feeding and depression of abomasal secretion in sheep elicited by elfazepam and 9-aza-cannabinol. Pharmacol Biochem Behav 11: 51-56.
81. Monteleone P, Matias I, Martiadis V, De Petrocellis L, Maj M, et al. (2005) Blood levels of the endocannabinoid anandamide are increased in anorexia nervosa and in binge-eating disorder, but not in bulimia nervosa. Neuropsychopharmacology 30: 1216-1221. [Crossref]

82. Holtkamp K, Herpertz-Dahlmann B, Hebebrand K, Mika C, Kratzsch J, et al. (2006) Physical activity and restlessness correlate with leptin levels in patients with adolescent anorexia nervosa. Biol Psychiatry 60: 311-313

83. Frieling H, Albrecht H, Jedtberg S, Gozner A, Lenz B, Wilhelm J, et al. (2009) Elevated cannabinoid 1 receptor mRNA is linked to eating disorder related behavior and attitudes in females with eating disorders. Psychoneuroendocrinology 34: 620-624.

84. Bermudez-Silva FJ, Cardinal P, Cota D (2012) The role of the endocannabinoid system in the neuroendocrine regulation of energy balance. J Psychopharmacol 26: 114-124. [Crossref]

85. Støving RK, Andries A, Brixen K, Flyvbjerg A, Hørder K, et al. (2009) Leptin, ghrelin, and endocannabinoids: potential therapeutic targets in anorexia nervosa. $J$ Psychiat Res 43: 671-679. [Crossref]

86. Fu J, Gaetani S, Oveisi F, Lo Verme J, Serrano A, et al. (2003) Oleylethanolamide regulates feeding and body weight through activation of the nuclear receptor PPARalpha. Nature 425: 90-93.

87. Gaetani S, Kaye WH, Cuomo V, Piomelli D (2008) Role of endocannabinoids and their analogues in obesity and eating disorders. Eat Weight Disord 13: e42-48. [Crossref]

88. Siegfried Z, Kanyas K, Latzer Y, Karni O, Bloch M, et al. (2004) Association study of cannabinoid receptor gene (CNR1) alleles and anorexia nervosa: differences between restricting and binging/purging subtypes. Am. J. Med. Genet. B Neuropsychiatr. Genet. 125B, 126-130.

89. Müller TD, Reichwald K, Brönner G (2008) Lack of association of genetic variants in genes of the endocannabinoid system with anorexia nervosa. Child Adolesc Psychiatry Ment Health 2: 33. [Crossref]

90. Monteleone P, Tortorella A, Martiadis V, Di Filippo C, Canestrelli B, et al. (2008) The cDNA $385 \mathrm{C}$ to A missense polymorphism of the endocannabinoid degrading enzyme fatty acid amide hydrolase (FAAH) is associated with overweight/obesity but not with binge eating disorder in overweight/obese women. Psychoneuroendocrinology 33: 546-550. [Crossref]

91. Monteleone P, Bifulco M, Di Filippo C, Gazzerro P, Canestrelli B, et al. (2009) Association of CNR1 and FAAH endocannabinoid gene polymorphisms with anorexia nervosa and bulimia nervosa: evidence for synergistic effects. Genes Brain Behav 8: $728-732$.

92. Ishiguro H, Carpio O, Horiuchi Y, Shu A, Higuchi S, Schanz N, Benno R, Arinami T, Onaivi E. S. (2010a). A nonsynonymous polymorphism in cannabinoid CB2 receptor gene is associated with eating disorders in humans and food intake is modified in mice gene is associated with eating diso
by its ligands. Synapse 64: 92-96.

93. Matias I, Di Marzo V (2007) Endocannabinoids and the control of energy balance. Trends Endocrinol Metab 18: 27-37. [Crossref]

94. Nelson K, Walsh D, Deeter P, Sheehan F (1994) A phase II study of delta-9tetrahydrocannabinol for appetite stimulation in cancer-associated anorexia. $J$ Palliat Care 10: 14-18.

95. Beal JE, Olson R, Laubenstein L, Morales JO, Bellman P, et al. (1995) Dronabinol as a treatment for anorexia associated with weight loss in patients with AIDS. $J$ Pain Symptom Manage 10: 89-97. [Crossref]

96. Bermudez-Silva FJ, Viveros MP, McPartland JM, Rodriguez de Fonseca F (2010) The endocannabinoid system, eating behavior and energy homeostasis: the end or a new beginning? Pharmacol Biochem Behav 95: 375-382. [Crossref]

97. Gross H, Ebert MH, Faden VB, Goldberg SC, Kaye WH, et al. (1983) A doubleblind trial of delta 9-tetrahydrocannabinol in primary anorexia nervosa. $J$ Clin Psychopharmacol 3: 165-171.

98. Naruse T, Amano H, Koizumi Y (1991) Possible involvement of dopamine D-1 and D-2 receptors in diazepam-induced hyperphagia in rats. Fundam Clin Pharmacol 5: 677-693. [Crossref]

99. Berry EM (2006) "Pilot study of THC (2.5mgx2) in 9 ambulatory AN patients," in The sixth Nordic Congress on Eating Disorders, Aarhus, Denmark.

100. Verty AN, Evetts MJ, Crouch GJ, Mcgregor IS, Stefanidis A, et al. (2011) The cannabinoid receptor agonist THC attenuates weight loss in a rodent model of activity-based anorexia. Neuropsychopharmacology 36: 1349-1358.

Copyright: (C2017 Milano W. This is an open-access article distributed under the terms of the Creative Commons Attribution License, which permits unrestricted use, distribution, and reproduction in any medium, provided the original author and source are credited. 